\title{
Context Exploration: An Example from the Implementation at Discrete Mathematics Classroom
}

\author{
Asrin Lubis ${ }^{1}$, Andrea Arifsyah Naution ${ }^{2}$, Yasifati $\mathrm{Hia}^{3}$, and Arnah Ritonga ${ }^{4}$ \\ \{asrinlubis@unimed.ac.id ${ }^{1}$, andrea86@unimed.ac.id ${ }^{2}$, yasifatihia@unimed.ac.id ${ }^{3}$, \\ arnahritonga@unimed.ac.id $\left.{ }^{4}\right\}$ \\ Medan State University ${ }^{1,2,3,4}$
}

\begin{abstract}
Context is recently claimed as an important aspect of mathematics learning in many countries, including Indonesia. Context proposes many opportunities for students to learn mathematics, including logic. In this case, the role of context is intended to enhance the students' desire towards logic and to develop a better insight into it to solve contextual problems. Moreover, context can provide students with different strategies for mathematical problems. Thus, this paper attempts to descriptively describe the results from a developmental study which aims to investigate the concept of context, context design and the examples of context used in discrete mathematics classrooms. Students' written works were also presented to show how students deal with context-based problems. Several articles and books related to the issues about what context basically means, why it is important in mathematics classrooms and how to design the context were also studied. Lecturers' awareness and perception about context were essentially needed in order to design the context that can be implemented in the classroom. The results of this study show that context can be a powerful instrument for students to construct their mathematical knowledge, especially in discrete mathematics, and to react with high-quality mathematical reasoning. Moreover, the lecturers need to acquire a better understanding of how to design context that bridge the students' previous knowledge to right mathematics procedure.
\end{abstract}

Keywords: Context, Context-Based Problems, Discrete Mathematics, Logical Reasoning, Higher Education.

\section{Introduction}

Several recent studies have claimed that living in present environment demands people to acquire not only problem-solving skills, but also it requires more than content knowledge (i.e. Ananiadou \& Claro, 2009; OECD, 2016; Wijaya et al., 2010). To practically meet the demands of living in this modern environment, people necessarily need to be capable of employing their skills and knowledge. One possible way to generate this condition is through educational practices, including higher education. In this case, Nasution \& Lukito (2015) stressed out that there exists a prominence to link these educational practices with students' daily lives. This means that there is a need for lecturers and educators to continuously eliminate the discrepancy between what students have learned in the classroom and how they implement the knowledge to solve real-life problems. Therefore, the educational practices 
should not only focus on transferring knowledge to the students, but also providing them with life skills (Tomlinson, 2004; Griffin, Care, \& McGraw, 2012).

In higher education, a number of empirical studies have been conducted to potentially develop students' ability to construct mathematical knowledge and to apply the concepts (i.e. Lubis \& Nasution, 2017; Reeves \& Clarke, 2003; Flach, 2007; E. Serna \& A. Serna, 2015). The National Council of Teachers of Mathematics (2000) emphasized that the curriculum of mathematics must focus on preparing the students for their next study and for solving dailylife problems at school, home and future work environments. The students' ability in order to apply mathematics concept in everyday life context is seen as a successful factor of mathematical competence in many countries (Eurydice, 2011), including Indonesia (The Indonesian Ministry of Research, Technology and Higher Education, 2017). At a wide scope, the important intention of real-life mathematics is to generate the pre-service teachers that they could prepare their students to participate in the Programme for International Student Assessment (PISA).

The argumentations about mathematics application in daily life have increased the important use of mathematics context-based problems with the real-life enactment in the teaching and learning process. In this case, students need to recognize the situation where the concept of mathematics is being used (Van Galen et al., 2005), including logic, and contexts are expected to develop their ability to transfer their knowledge (De Lange, 2003). In line with those two statements, NCTM (2000) emphasized that it is necessary to provide the students with occasions to deal with contextual problems in mathematics. In some studies conducted by PISA show that tasks would be authentic if they could be essentially embedded in various real-life situations and had a context in mathematics to deal with the problems (OECD, 2003).

Based on the above description about the importance of context in the mathematics teaching and learning process, we attempt to conduct a study which is aimed to explore context used in teaching mathematics at higher education, including logic. Several examples of context implementation in teaching logics were depicted from recent studies to show how context could construct students' mathematical knowledge. Therefore, the main question "How can we support the lecturer to design meaningful context to teach logic in the classroom?" is explored in this paper..

\section{Theoretical Framework}

\subsection{Context-Based Problems}

The term "context-based problems" have been introduced in many studies and its importance in teaching and learning process, especially in mathematics classroom. A number of terminologies have been addressed to describe what context-based problem certainly means. In this case, contextual problems should be able to link what students have experienced and the intended mathematical concepts (Bustang, 2014). In addition, Van den Heuvel-Panhuizen (1999) highlighted that contextual problems allow students to start with lower level strategies, such as drawing pictures and doing several manipulatives. Hence, the context-based problems providemany opportunities for the students to overcome the problems at different levels of understandings.

The existence of contexts is also described by Van den Heuvel-Panhuizen (2005) who explicitly stated that a 'context in mathematical problem' should be authentic for students and 
should mandatorily require them to think in the scope of the context of the problem. "By imagining themselves in the situation to which the problem refers, the students can solve the problem in a way that was inspired, as it were, by the situation" (Van den Heuvel-Panhuizen, 2005 , p. 6). It means that context-based problems can encourage students to apply strategies to seek a solution, such as using pictures, tables, or graphs. Another term that is used to refer to problems situated in reality is 'modeling tasks' (see, e.g. Blum, 2011; Maass, 2010; Tasova \& Delice, 2012). Modeling tasks emphasize modeling or translation between real-world contexts and mathematics.

Considering the aforementioned descriptions of problems that use contexts, in this article we define a context-based mathematics problem as a mathematics task that is situated in realworld settings and provides elements or information that need to be mathematically organized and modeled. We do not utilize the term word problems or story problems since the settings can likewise be delineated in non-verbal depictions, for example, pictures. An outcome of our definition is that we apply a high standard to the accompanying qualities of context-based problems: the undertakings have pretty much data than what is expected to discover the solution and should not obviouslyprovide the required mathematical formulas.

\subsection{What is a Good Context?}

Learning mathematics with inquiry lessons at university can sometimes begin with a context problem. The emphasis of the problem is to provide the students a space where they can apply the mathematical concepts they have learned to deal with contextual problems and the ideas that the students encounter (Wijaya et al., 2010). Therefore, it is necessary to give the students much time to think and to undergo exploration to discuss their ideas in determining the problem solutions.

Thus, what is a good context in mathematics? According to Van Galen (2018), a good context is a real-world context that entails meaningful and interesting problem which can possibly stimulate the students to think. Moreover, a good context can be designed through an open problem that cannot be answered by a standard algorithm and therefore encourages the students to apply their own explanations..

\section{Methodology}

\subsection{The participant}

This study was conducted in the third semester at mathematics department, Medan State University. During conducting this study, we engaged 45 mathematics-education students who enrolled mathematics discrete course. In addition, the lecturer who taught discrete mathematics in the classroom was also involved.

\subsection{Data Collection}

In order to acquire the information about the use of context, we include different types of data, such as video recordings, students' written works, interviews and field notes. In this case, the video recording was installed to record what the students do in during conducting this study. All the students' written works and activities along the teaching and learning process 
were recorded so they can be descriptivelyanalyzed. The data from the students' written works were collected to acquire information about the students' strategies to solve context-based discrete problems. A pretest was conducted at the beginning of this study to was to discover whether the students already knew what were intended for them to learn or not. In this study, interview was also carried out to several students before the teaching and learning process.

During the interview, students were asked to explain what they did to answer the problems in the pretest and to communicate their argumentations on how they got the answer. The results of the pretest and the interview showed that the students had no understanding about discrete mathematics.

\subsection{Research Design}

Aforementioned, this study was conducted to positively contribute to the development of teaching and learning process in discrete mathematics classroom. In this study, five questions related to discrete mathematics were designed to get the impression how they deal with the context-based problems with their understanding. Several examples were depictedto demonstrate these contexts were implemented in discrete mathematics classroom.

\subsection{The Problems}

1. Badren wants to give two boxes to his friend. Both of the boxes contain present or empty. The first box was written "At least one of these boxes contains present". The second box was written "The first box is empty". Badren tells his friend that both of the writings are true or false.

Based on your opinion, which box should his friend choose?

2. Given a graph $\mathrm{G}$ which is a complete graph with 28 edges. According to your opinion, how many vertices does the graph have?

\subsection{How to Solve the Problems?}

To solve the problem, the students need to better understand the situation in which the mathematical concept is being used (Nasution \& Lukito, 2015). In this case, we provide one possible alternative that the students could possibly do to deal with the problems.

\section{Problem 1}

This problem aimed to test the students' ability to better understand about the value of two disjunctive prepositions $(\mathrm{P}(\mathrm{x}) \vee \mathrm{Q}(\mathrm{x}))$. From this problem, we can observe that the first box is written "At least one of these boxes contains present" and it is written "The first box is empty" in the second box. The last statement "Badren tells his friend that both of the writings are true or false" can be the beginning way in order to solve this problem. The yielding explanation about this problem as follows.

$\mathrm{P}(\mathrm{x})$ : At least one of these boxes contains present

$\mathrm{Q}(\mathrm{x})$ : The first box is empty

In order to check the value of these two statements, see the truth table for disjunction of two prepositions in Table 1 below. 
Table 1. The truth table of disjunction

\begin{tabular}{ccc}
\hline $\mathbf{P}(\mathbf{x})$ & $\mathbf{Q}(\mathbf{x})$ & $\boldsymbol{P}(\boldsymbol{x}) \vee \boldsymbol{Q}(\boldsymbol{x})$ \\
\hline True & True & True \\
True & False & True \\
False & True & True \\
False & False & False \\
\hline
\end{tabular}

Based Badren's statement "both of the writings are true or false", we can conclude that the value of both preposition $(\mathrm{P}(\mathrm{x})$ and $\mathrm{Q}(\mathrm{x}))$ is true. Thus, his friend should choose the second box.

Problem 2

This problem is designed to find out the students' basic understanding of graphs, especially complete graph applications. Here, students are given problems to determine the number of vertices that exist if a complete graph has 28 pieces. To solve this problem, students must understand the meaning of a complete graph. Because complete graphs are simple graphs where each node is close together, the number of paths can be determined using sequence series.

$(n-1)+(n-2)+(n-3)+(n-4)+(n-5)+(n-6)+(n-7)+(n-8)=$ The number of vertices

$8 \mathrm{n}-36=28$

$8 \mathrm{n} \quad=28+36$

$8 \mathrm{n}=64$

$\mathrm{N} \quad=8$

So, a complete graph, which has 28 sides, has 8 vertices

\section{Result}

Problem 1

In order to solve the first problem, some students come up with drawing pictures. One possible reason is that the students use the pictures to represent the problem situation. The example of this strategy can be seen in Figure 1 below.

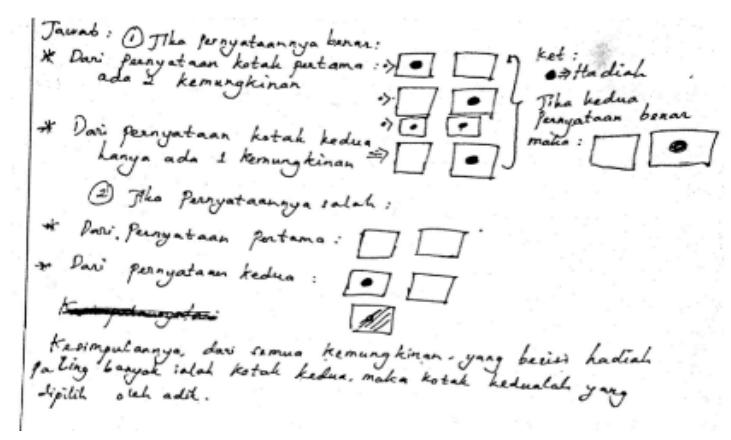

Fig. 1. Students strategy to solve problem 1 
Based on Figure 1, we can obviously see that the student attempt to solve the first problem by using his own pictures. Firstly, he wrote if the statements are true, then there will be two possible conditions based on the first statement. This student drew two boxes with a black dot inside the box to represent the box that contains present. He arrived at the first box contains present and the second box is empty (condition I) and vise versa (condition II). Secondly, if the statements are incorrect, then he also found two possible conditions. Based on the first statement, the two boxes are empty; on the other hand, the first box contains present and the second box does not (from the second statement). Thus, he concluded that the second box must be chosen since it contains present.

In this case, the student's answer is correct; however, he did not provide sufficient argumentations that can support his answer. The reason why he concluded such answer is still unclear and needs further exploration. However, this type of answer can be used by the lecturer as a way to develop his reasoning.

\section{Problem 2}

In determining the number of nodes, students generally solve the questions using manipulatives and word descriptions. Some students use pictures, but they try to find the appropriate picture to be the answer to that question. Student strategies can be seen clearly in Figure 2 below.

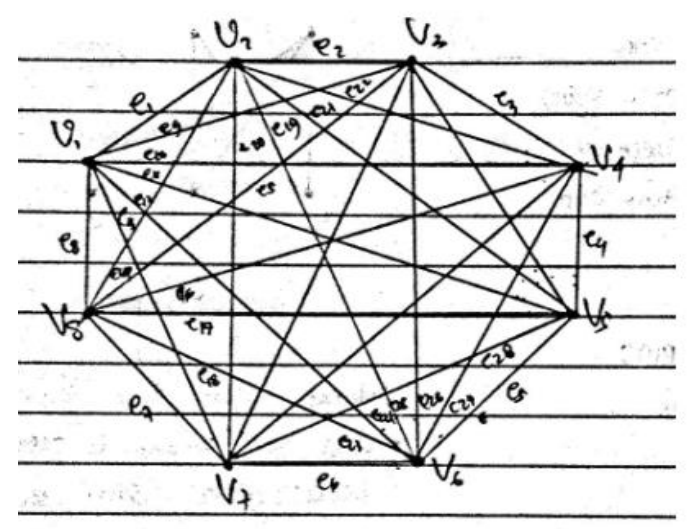

Fig. 2. Strategy with Drawing Picture

In Figure 2 above, it can be seen clearly that the student already has a basic understanding of the graph. In the event that the student makes eight vertices which are then named $\mathrm{V}(\mathrm{G})=$ $\{\mathrm{v} 1, \mathrm{v} 2, \mathrm{v} 3, \mathrm{v} 4, \mathrm{v} 5, \mathrm{v} 6, \mathrm{v} 7, \mathrm{v} 8\}$ and names each path with $\mathrm{E}(\mathrm{G})=\{\mathrm{e} 1, \mathrm{e} 2, \mathrm{e} 3, \mathrm{e} 4, \mathrm{e} 5, \mathrm{e} 6, \ldots$, e28). Here, the student's answer is correct that the complete graph has eight vertices. However, it is still unclear how he got the eight nodes because there was no explicit explanation.

In addition, other students complete the first question using the Word Description as shown in Figure 3 below.

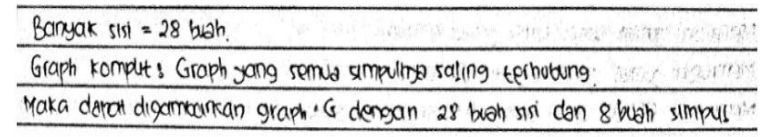

Fig.3. Strategy with Word Descriptions 
From Figure 3 above, it can be seen clearly that the student already has a standing point regarding complete graphs because he writes "complete graphs: graphs that all vertices are connected". However, in completing this first question the student only wrote a graph G can be described with 28 sides and 8 vertices. The same thing with students in Figure 1 above. Although the student's answer is correct, there is no sufficient explanation about how he got the 8 vertices. To clarify the answer, we conducted interviews with students.

From Figure 2 and Figure 3 above and the results of the interview, it can be concluded that students have an understanding of the graph, but they still find it difficult to express "why" they can get results like that and "how" the way they get it. This can be seen from the results of their work, namely there is no in-depth explanation of the answers they get (see Figure 2 and Figure 3).

\section{Conclusion}

We are convinced that it takes time to develop students' mathematical thinking, especially in discrete mathematics course. In answering the crucial question of this particular study, we used the analysis of the data collection, such as students' written work and interview. One possible way to get the students' reasoning on how they solve logical problems is by the commencement of a contextual situation. Commencing a contextual problem can be meaningful if there is a good problem in it.

A good context is a real-world context that entails meaningful and interesting problem which can possibly stimulate the students to think. Moreover, a good context can be designed through an open problem that cannot be answered by a standard algorithm and therefore encourages the students to apply their own explanations. Some examples can be obviously seen through the above students' written work. For example, some students come up with drawing pictures. One possible reason is that the students use the pictures to represent the problem situation, in order to solve the first problem (see Figure 1). Other students come up with their argumentations (word description).

Based on Figure 1, we can obviously see that the student attempt to solve the first problem by using his own pictures. Firstly, he wrote if the statements are true, then there will be two possible conditions based on the first statement. This student drew two boxes with a black dot inside the box to represent the box that contains present. He arrived at the first box contains present and the second box is empty (condition I) and vise versa (condition II). Secondly, if the statements are incorrect, then he also found two possible conditions. Based on the first statement, the two boxes are empty; on the other hand, the first box contains present and the second box does not (from the second statement). Thus, he concluded that the second box must be chosen since it contains present.

In this case, the student's answer is correct; however, he did not provide sufficient argumentations that can support his answer. The reason why he concluded such answer is still unclear and needs further exploration. However, this type of answer can be used by the lecturer as a way to develop his reasoning.

Another instance can be depicted in the second problem. In determining the number of nodes, students generally solve the questions using manipulatives and word descriptions. Some students use pictures, but they try to find the appropriate picture to be the answer to that question. Student strategies can be seen clearly in Figure 2. In Figure 2 above, it can be seen clearly that the student already has a basic understanding of the graph. In the event that the 
student makes eight vertices which are then named $V(G)=\{v 1, v 2, v 3, v 4, v 5, v 6, v 7, v 8\}$ and names each path with $\mathrm{E}(\mathrm{G})=\{\mathrm{e} 1, \mathrm{e} 2, \mathrm{e} 3, \mathrm{e} 4, \mathrm{e} 5, \mathrm{e} 6, \ldots, \mathrm{e} 28)$. Here, the student's answer is correct that the complete graph has eight vertices. However, it is still unclear how he got the eight nodes because there was no explicit explanation.

In addition, other students complete the first question using the Word Description as shown in Figure 3. From Figure 3 above, it can be seen clearly that the student already has a standing point regarding complete graphs because he writes "complete graphs: graphs that all vertices are connected". However, in completing this first question the student only wrote a graph $\mathrm{G}$ can be described with 28 sides and 8 vertices. The same thing with students in Figure 1 above. Although the student's answer is correct, there is no sufficient explanation about how he got the 8 vertices. To clarify the answer, we conducted interviews with students.

From Figure 2 and Figure 3 above and the results of the interview, it can be concluded that students have an understanding of the graph, but they still find it difficult to express "why" they can get results like that and "how" the way they get it. This can be seen from the results of their work, namely there is no in-depth explanation of the answers they get (see Figure 2 and Figure 3).

\section{References}

[1]Ananiadou, K., \& Claro, M., 21st Century Skills and competencies for new millennium in OECD countries. OECD Education Working Papers, No. 41. OECD Publishing, 2009.

[2]Blum, W. Can modelling be taught and learnt? Some answers from empirical research. In G. Kaiser, W. Blum, R. B. Ferri \& G. Stillman (Eds.), Trends in teaching and learning of mathematical modelling (pp. 15-30). New York: Springer, 2011.

[3]Griffin, P., Care, E., \& McGaw, B., The changing role of education and schools. In P. Griffin, B. McGraw \& E. Care (Eds.), Assessment and Teaching of 21st Century Skills (pp. 1-16). New York: Springer, 2012.

[4]Lubis, A., Nasution, A. A., How Do Higher-Education Students Use Their Initial Understanding to Deal with Contextual Logic-Based Problems in Discrete Mathematics?. International Education Studies, pp. $72-86,2017$.

[5]Maass, K. Classification scheme for modelling tasks. Journal für Mathematik-Didaktik, 31(2), 285-311, 2010.

[6]Nasution, A., \& Lukito, A., Developing Students' Proportional Reasoning through Informal Way. Journal of Science and Mathematics Education in Southeast Asia, 38(1), 77-101, 2015.

[7]OECD, Skill Metter: Further Results from the Survey of Adults Skills. Paris: OECD Publishing, 2016.

[8]Tasova, H. I., \& Delice, A. An analysis of pre-service mathematics teachers' performance in modelling tasks in terms of spatial visualisation ability. Research in Mathematics Education, 14(3), 297-298, 2012.

[9]Tomlinson, M., 14-19 Curriculum and qualifications reform. Final report of the Working Group on 14-19 Reform. London: Department for Education and Skills, 2004.

[10]Van den Heuvel-Panhuizen, M., The role of context in assessment problems in mathematics. For the Learning of Mathematics, 25(2), 2-9 + 23, 2005.

[11]Van Galen, F.\& Van Eerde, D., Mathematical Investigations For Primary Schools. Utrecht: Utrecht University, 2018.

[12]Widjaya, W., Dolk M., Fauzan A., The Role of Context and Teacher's Questioning To Enhance Students' Thinking. Journal of Science and Mathematics Education in Southeast Asia, 33(2), pp. 168 $186,2010$. 